54, 3, pp. 679-690, Warsaw 2016

DOI: $10.15632 /$ jtam-pl.54.3.679

\title{
EXPERIMENTAL INVESTIGATION OF AN ENERGY HARVESTING ROTARY GENERATOR-MR DAMPER SYSTEM
}

\author{
BOGDAN SAPIŃSKI \\ AGH University of Science and Technology, Department of Process Control, Kraków, Poland \\ e-mail:deep@agh.edu.pl
}

\begin{abstract}
The study investigates an energy harvesting system utilising rotary motion. The system has three components: a rotary MR damper to vary the damping characteristics, a rotary power generator (energy extractor) producing electrical power, and a conditioning electronics unit to interface directly with the damper and the generator. The objective of the study is to examine the system performance through experiments. The paper outlines the structure of the damper and the generator, provides selected results of examination of the system components and the whole system under idle run and under load for the assumed speed range. The results demonstrate that the system is adaptable to external excitations, does not require an extra power supply and provides a smart solution with potential applications to rotary motion control.
\end{abstract}

Keywords: MR damper, generator, conditioning electronics, experimental testing

\section{Introduction}

Energy harvesting from vibrations is one on the research areas that has recently attracted a great deal of scientific and engineering interest. A comprehensive overview of the state-of-the-art in vibration energy harvesting technologies has been provided by Priya and Inman (2009). The book presents the current state of knowledge and achievements of leading researchers both in academia and industry. Alongside, many articles have been published on the topic of vibration energy harvesting systems where an external power supply unit is replaced by energy extractors employing various mechanisms of energy conversion.

The present study focuses on a regenerative rotary system utilising an electromagnetic mechanism of energy conversion. The system incorporates three basic components: a rotary MR damper, a rotary power generator and a conditioning electronics unit. The MR damper is a semi-active current-driven device employing the real-time control of the torque output. The energy extractor is a rotary generator which converts mechanical energy into electrical energy. The energy harvested from external excitations via the generator is used for controlling the torque output of the damper. The conditioning electronics unit develops conditioning-processing circuits for improving the generator output signal.

The ability to convert mechanical into electrical energy to power an MR damper brings numerous benefits. The power generator-MR damper system forms a stand-alone regenerative device that seems to be a promising solution to control of motion. Such a system is capable of operation with no need for external power supply connections.

The concept of utilising energy recovered from structural vibrations to power MR dampers was first suggested in the work by Scruggs and Lindner (1999). Since then, a great number of publications have appeared, summarising the research results in this field. For example, Cho et al. (2007) developed a special structure of an electromagnetic generator to be used with an MR damper. Hong et al. (2007) investigated an MR damper-electromagnetic generator system 
in seismic protection applications. Avadhany et al. (2008) developed a regenerative damper intended for automotive light-duty and military vehicle applications.

Major advances have been made in this field, enabling MR dampers to be self-powered (no extra power supply needed) and self-sensing, where information about relative velocity across the damper is derived basing on voltage produced by the generator. Choi and Werely (2009) embarked on the study of feasibility and effectiveness of a self-powered MR damper, using a spring-mass electromagnetic induction device. Wang and Wang (2010) developed a self-sensing MR damper to implement integrated relative displacement sensing and controllable damping. Jung et al. (2010) demonstrated that an electromagnetic generator incorporated in an MR damper-based system can act as a velocity-sign sensor. Sapiński (2011) investigated a self-powered and selfsensing control system comprising both a power generator and an MR damper. Chen and Liao (2012) reported on the energy-harvesting MR damper integrating energy harvesting, dynamic sensing and MR damping technologies in a single device and tested a prototype. Liao and Chen (2012) presented a conceptual design of such a device patented. Li et al. (2013) came up with an innovative concept of a mechanical motion rectifier which converts bidirectional into unidirectional motion. Sapiński (2014) developed a prototype of an energy-harvesting linear damper and provided the results of experimental testing.

It is worthwhile to mention that recent developments in regenerative MR actuators using the energy conversion mechanism included mostly shock absorbers. Research efforts have focused on regenerative MR shock absorbers in automobiles, railway vehicles and civil structure applications.

The present study focuses on an energy harvesting system utilising rotary motion. The system incorporates a rotary MR damper, a rotary generator and a conditioning electronics unit (Fig. 1) allowing the energy of external excitations to be recovered while the system adjusts itself to applied excitations. The structure design and experimental results obtained from the testing done on the system components and on the system as a whole are summarized. It is demonstrated that the system has the self-powered capability (operates without a need for an extra power supply).

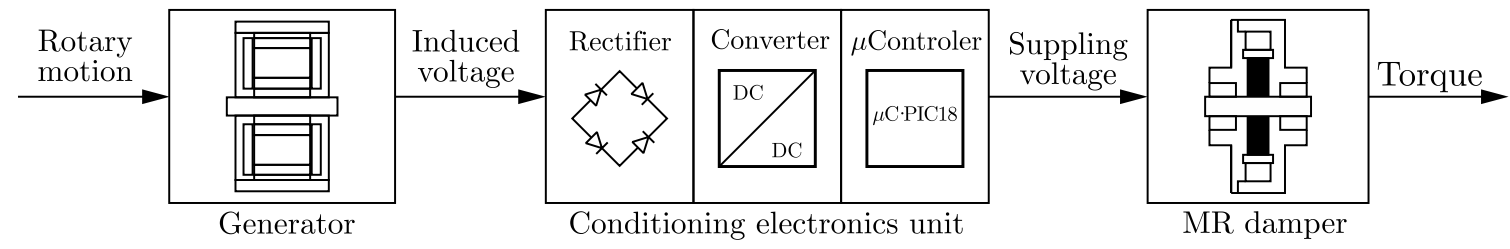

Fig. 1. Schematic diagram of the examined system

The paper is organized as follows. In Section 2, the structure of the damper is described and selected characteristics of the device are provided. In Section 3, the structure of the generator is outlined and measurement results are presented. Section 4 characterizes the conditioning electronics unit and discusses results of its experimental tests. Section 5 presents the experimental testing of the whole system. The final conclusions are given in Section 6 .

\section{MR damper}

The structure of the MR damper is shown in Fig. 2. On shaft (2) in the damper, made of nonmagnetic steel and supported on two ball bearings (3), there are four mobile and three immobile plates (4) made of magnetic steel. These plates are attached to housing (6) via closing cover (1) made of low carbon steel. Between the plates, inside the ferromagnetic core, there is control coil (5). The coil winding comprises 610 turns, wound with copper wire $0.48 \mathrm{~mm}$ in diameter. 
The space between the plates is filled with $45 \mathrm{ml}$ of MR fluid Basonetic 2040, manufactured by the BASF company. The external diameter and height of the device is $100.6 \mathrm{~mm}$ and $30 \mathrm{~mm}$, respectively. The gap between the neighbouring plates is $0.5 \mathrm{~mm}$.

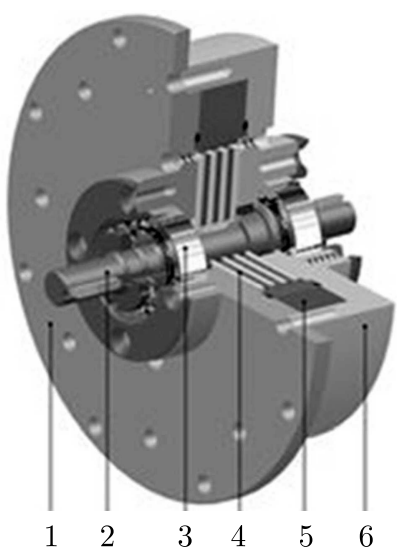

Fig. 2. Structure of the damper: 1 - cover, 2 - shaft, 3 - bearing, 4 - plates, 5 - control coil, 6 - housing

The damper described was tested experimentally. In the first step, the testing was done on the control coil. The step-like input voltages of amplitudes in the range $(2,16) \mathrm{V}$ were applied to the coil, and the current level in the system was measured accordingly. Figure 3 illustrates the current response of the coil to the voltage input with the amplitude $8 \mathrm{~V}$. The steady state value of the current is found to be $0.55 \mathrm{~A}$.

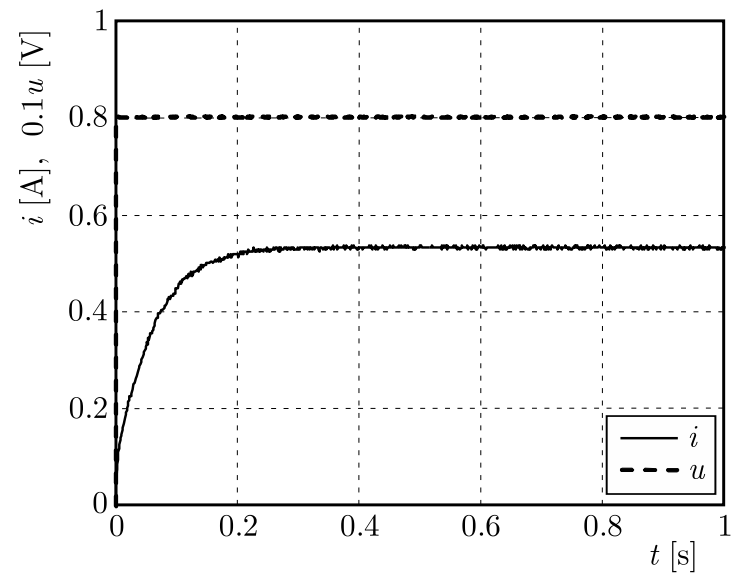

Fig. 3. Current response of the control coil to the step-like voltage input with the amplitude $8 \mathrm{~V}$

The time constant of the control coil determined through the testing was found to be $\tau_{d}=53 \mathrm{~ms}$. Knowing the time constant and having measured the coil resistance $\left(R_{d}=14.67 \Omega\right)$, the coil inductance was derived accordingly $L_{d}=0.772 \mathrm{H}$.

Further tests were conducted to determine the relationship between the torque $T$ and the rotational speed $w$ for various levels of the current $I$ in the coil and the relationship between the torque and the increasing and decreasing current level in the control coil for various speed levels. The speed range was $(10,250) \mathrm{rpm}$, and the current level varied in the range $(0,1.5) \mathrm{A}$. Figure $4 \mathrm{a}$ plots the torque vs. speed characteristics for the current values: 0, 0.2, 0.6, 1.0, 1.5 A. It is clearly apparent that the minimal torque value is $0.5 \mathrm{Nm}(I=0 \mathrm{~A})$ and the maximal is equal to $10.5 \mathrm{Nm}(I=1.5 \mathrm{~A})$. Figure $4 \mathrm{~b}$ plots the dependence of the torque on the increasing and decreasing current level in the coil at the speed of $100 \mathrm{rpm}$, revealing a narrow hysteresis in the damper behaviour. 
(a)

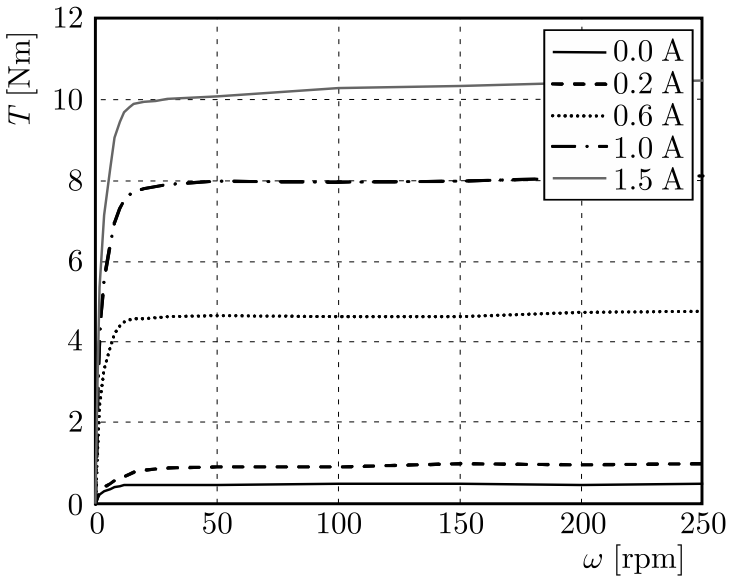

(b)

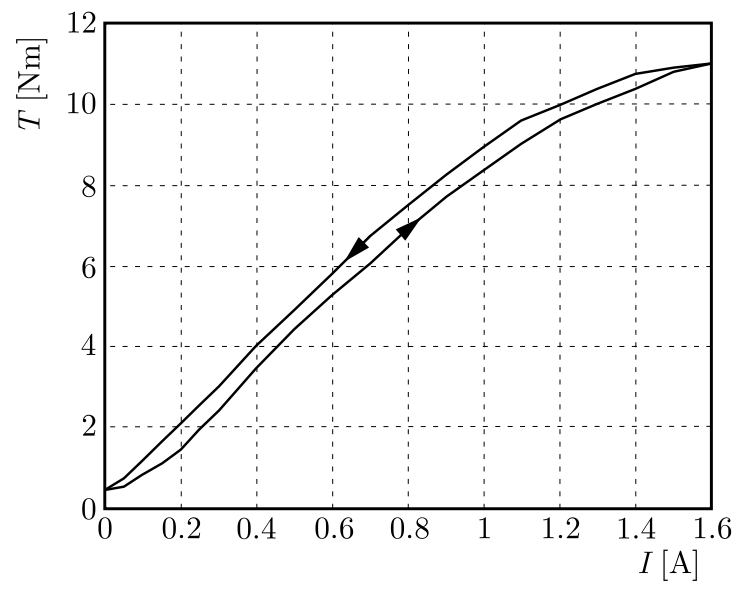

Fig. 4. (a) Torque vs. speed for various current level in the control coil. (b) Torque vs. current in the control coil; $\omega=100 \mathrm{rpm}$

\section{Generator}

The structure of the generator is shown in Fig. 5. It comprises an axis-positioned armature and a cylindrical inductor, which acts as a housing. The inductor with external diameter of $67.5 \mathrm{~mm}$, has 28 radially magnetised permanent magnets (1), forming $p=14$ pairs of magnet poles arranged symmetrically inside its circumference, such that they face one another with their opposite poles. The armature, comprising 14 rectangular frames (2) is fixed on axis (5) with ball bearings (6). The number of frames is equal to that of the pole pairs in the inductor. The frames, made of ferromagnetic steels, are arranged radially and attached to carcass (4) made of a dielectric material. Inside the frame, there is coil (3) comprising 306 turns, wire-wound on the carcass with the copper wire $0.2 \mathrm{~mm}$ in diameter. The magnetic circuit in the generator is made of silicon steel laminations.

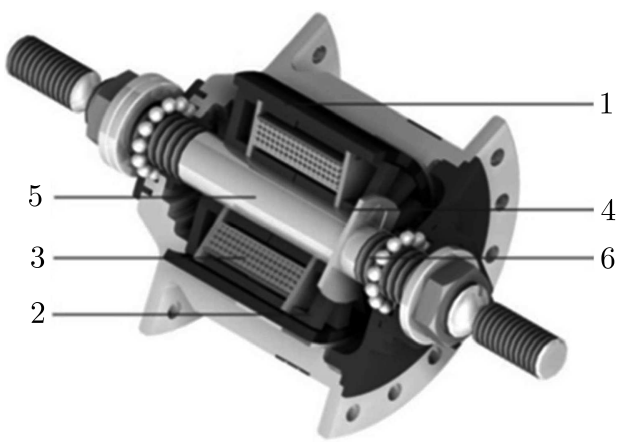

Fig. 5. Structure of the generator: 1 - magnets, 2 - frames, 3 - coil, 4 - carcass, 5 - shaft, 6 - bearing

Figure 6 illustrates how a time-variant magnetic flux is generated in a single frame of the generator. The condition when the pole pieces are positioned beneath magnets(1) with opposite poles is shown in Fig. 6a. The magnetic field having the flux density $B$ (generated by the magnets) penetrates the frame closing the magnetic circuit. Coil (3) encompasses the resultant flux, being the sum of magnetic fluxes in all frames (2). As the inductor rotates, the pole pieces in frame move beneath the magnets with the opposite poles (see Fig. 6b). As a result, the direction of the resultant magnetic flux permeating the coil is reversed. Thus generated variable magnetic flux will then induce the emf in the coil.

The generator described was tested experimentally. In the first step, the testing was done on the coil in the generator. The step-like input voltage $u$ of amplitudes in the range $(0,2.5) \mathrm{V}$ was applied and the current level $i$ in the system was measured accordingly. Figure 7 illustrates 
(a)

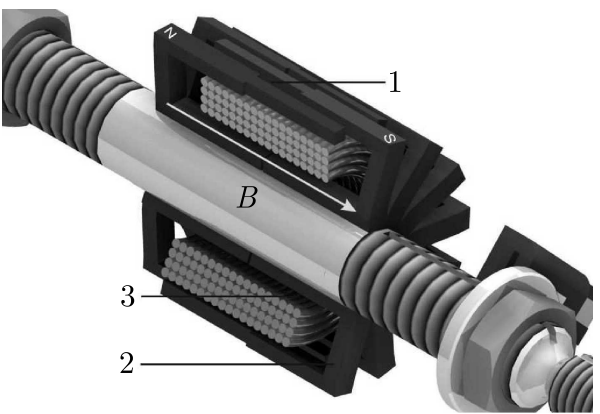

(b)

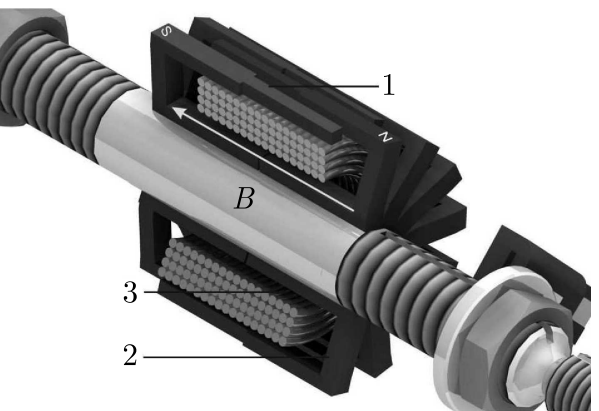

Fig. 6. Operating principle of the generator

the current response of the coil to the voltage input with the amplitude $1 \mathrm{~V}$. The steady state value of current was found to be about $0.5 \mathrm{~A}$. The measured current responses were utilised to derive the time constant of the control coil, which was found to be $\tau_{g}=11 \mathrm{~ms}$. With the time constant being known and the coil resistance being measured $\left(R_{g}=2.7 \Omega\right)$, the coil inductance was derived accordingly $L_{g}=0.031 \mathrm{H}$.

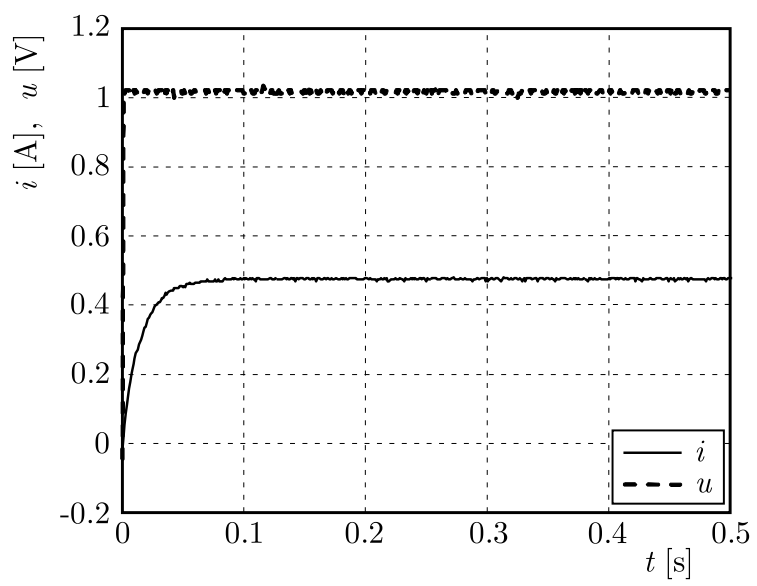

Fig. 7. Current response of the generator coil to the step-like voltage input with the amplitude $1 \mathrm{~V}$

Further tests were conducted to test the generator performance under idle run and under load applied to the control coil in the MR damper, for the speed range $(10,250) \mathrm{rpm}$. The tests involved measurements of the emf in the generator (idle run) and of the voltage and the current level in the control coil (under load). The equivalent electric circuit of the generator and the damper is depicted in Fig. 8.

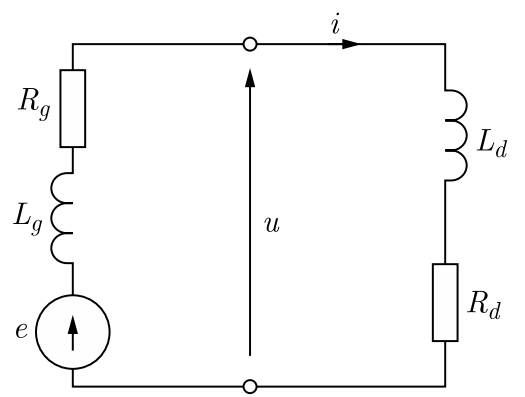

Fig. 8. Schematic diagram of the generator-MR damper circuit

Figures $9 \mathrm{a}$ and $9 \mathrm{~b}$ show selected results of the experimental tests. Plots in Fig. 9a represent time patterns of the emf in the generator coil whilst plots in Fig. 9b show time patterns of the voltage and current in the damper coil (under load), obtained at $100 \mathrm{rpm}$. It appears that the 
maximal value of the measured emf is $17 \mathrm{~V}$ and the maximal values of voltage and current in the control coil are $12 \mathrm{~V}$ and $0.2 \mathrm{~A}$, respectively. The relationships between the $\mathrm{rms}$ value of emf, $r m s$ value of current and the speed, determined in the range $(10,250) \mathrm{mm} / \mathrm{s}$, are given in Fig. 10 . It is clearly apparent that these quantities in function of velocity will only slightly deviate from the linear pattern.

(a)

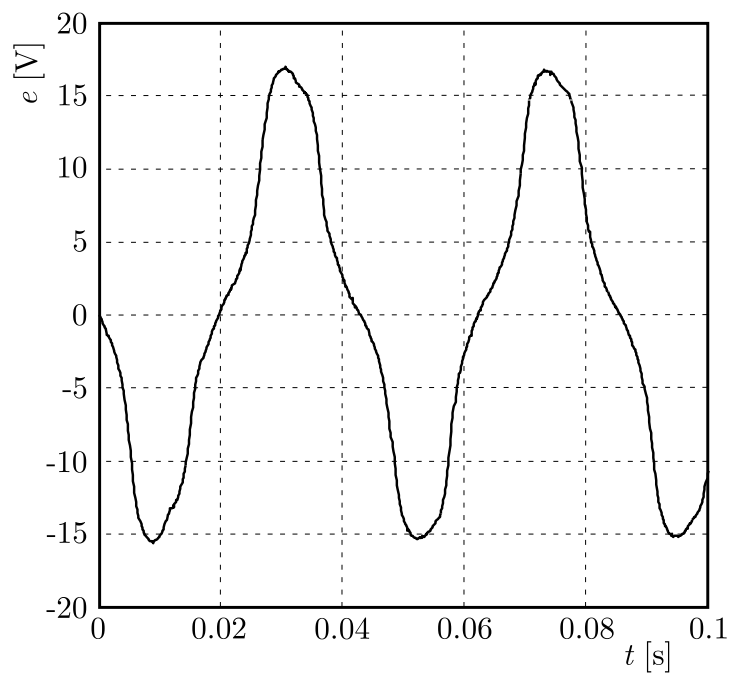

(b)

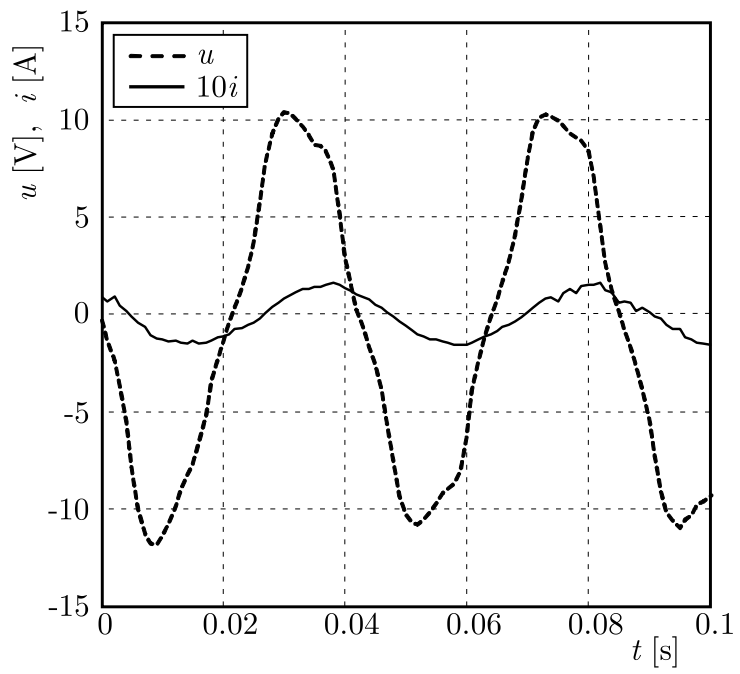

Fig. 9. Time histories of emf $e$ (a) and of voltage $u$ and current $i$ (b) in the generator coil; $\omega=100 \mathrm{rpm}$

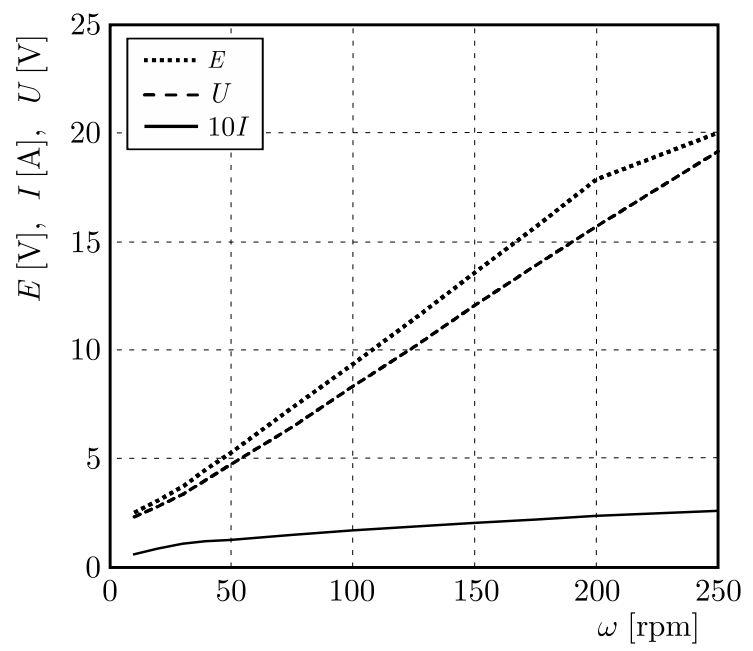

Fig. 10. rms values of emf in the generator coil and voltage and current in the control coil vs. speed

\section{Conditioning electronics}

The conditioning electronics unit creates circuits for improving the output voltage in the generator. A block diagram of the unit is shown in Fig. 11. It incorporates Graetz bridge based on the Schottky diodes (http://www.nxp.com), a converter $(0.8 \mathrm{~V} / 8 \mathrm{~V})$, Hall sensor based on the ACS 712 system (http://www.allegromicro.com), a signal acquisition and processing block and a controller equipped with multiprocessor PIC 18 (Microchip Technology Inc., 2010). The voltage $u_{0}$ produced by the generator is rectified (voltage $u_{1}$ ) and delivered via the converter (voltage $u_{c}$ ) and the photo relay $\mathrm{K}_{a}$ to activate the damper control coil (voltage $u$ ). The controller regulates the photo relay $\mathrm{K}_{a}$ and supervises the interaction with the PC via a USB port. 


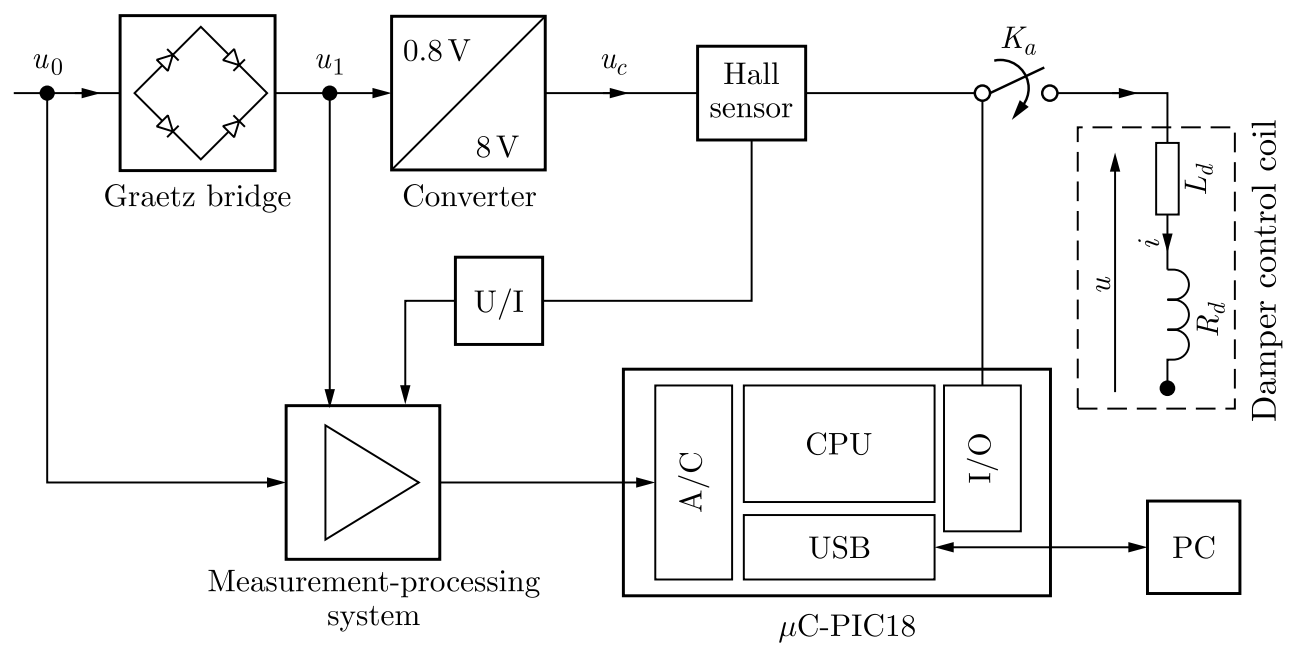

Fig. 11. Block diagram of the conditioning electronics unit

The unit described was tested experimentally. Two cases were considered in the experiments (see Fig. 12). In first case, the damper coil was not supplied (idle run) whilst in case 2, the damper coil was supplied with voltage controlled by the photo relay $\mathrm{K}_{a}$ equipped with a controller (under load).

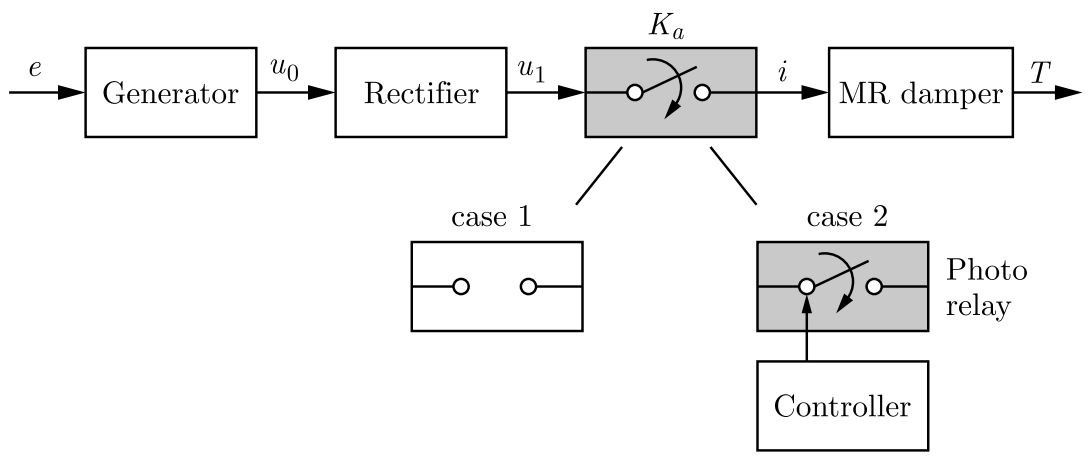

Fig. 12. Block diagram of the system in case 1 and 2

The idle-run testing began at the speed $10 \mathrm{rpm}$, and was gradually increased up to $40 \mathrm{rpm}$. Selected results are shown in Fig. 13a, plotting time histories of the emf in the generator voltage $\left(u_{0}\right)$ and the output voltage from the converter $u_{c}$ at speed $40 \mathrm{rpm}$. The voltage $u_{c}$ reaches the value $8 \mathrm{~V}$, which is the maximal admissible level for the type of converter employed in the unit.

The tests conducted under the loading conditions revealed that at speed $40 \mathrm{rpm}$ the amplitude of the output voltage from the generator would go down to about $1.1 \mathrm{~V}$, making the correct operation of the converter impossible. That is why the results of the tests conducted under the loading conditions are given for the speed being twice as high, i.e. $80 \mathrm{rpm}$ (Figs. 13b-14b). The plots illustrate the time histories of the output voltage from the generator $u_{0}$ and voltage $u$ and the current in the damper coil $i$. The voltage is found to oscillate around $6 \mathrm{~V}$ and the current approaches $0.2 \mathrm{~A}$. The discrepancies between the calculated and measured data of the emf, voltage and current in the damper coil are attributable to differences in the values assumed for simulations and the actual parameter values of the unit components, and to the fact that the converter frequency was not included in the simulation procedure. 
(a)

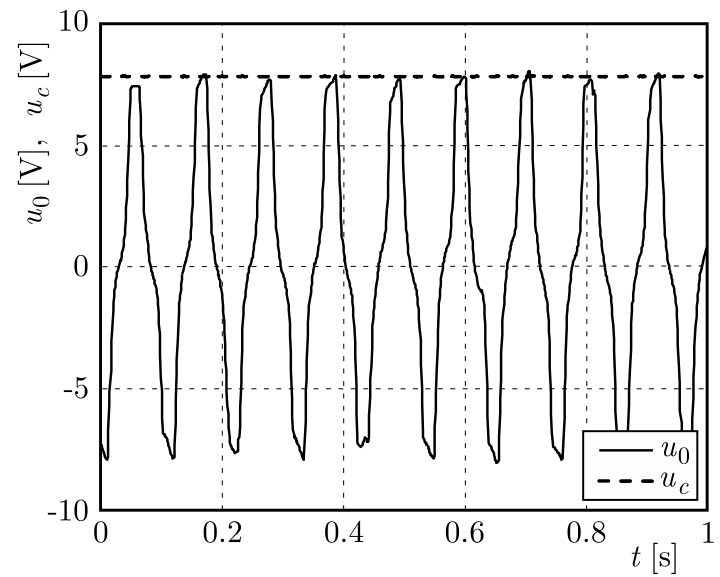

(b)

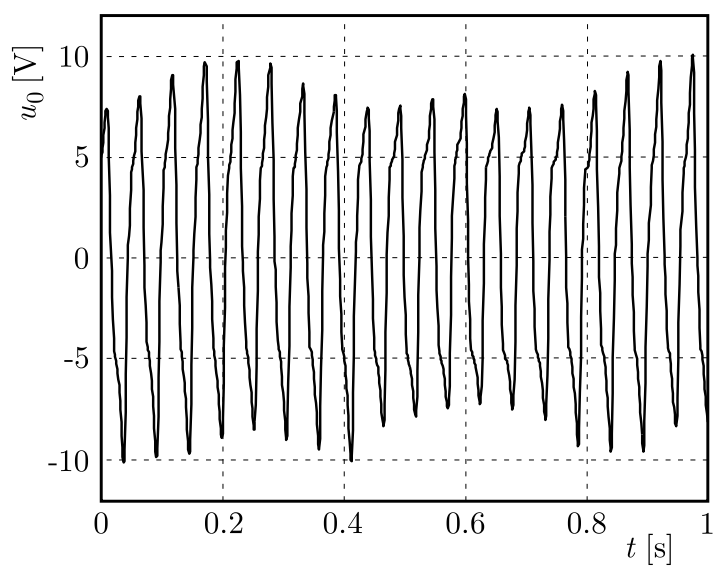

Fig. 13. Time histories of output voltage from: (a) the converter and generator in case $1(\omega=40 \mathrm{rpm})$, (b) the generator in case $2(\omega=80 \mathrm{rpm})$

(a)

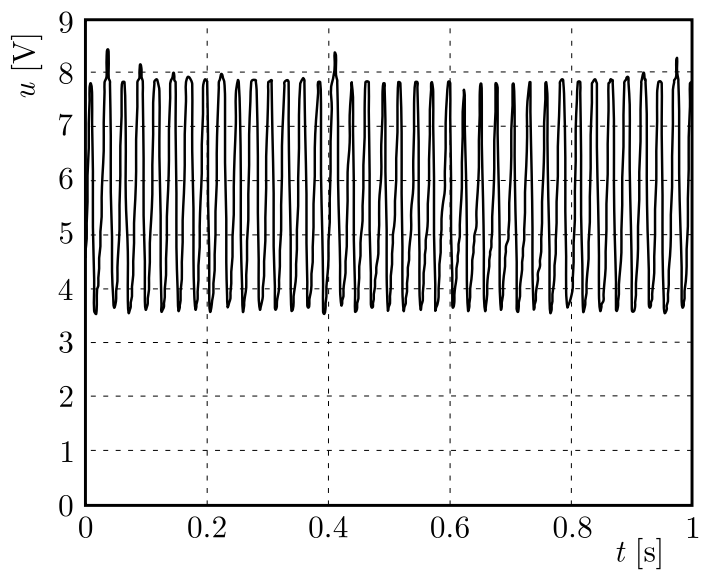

(b)

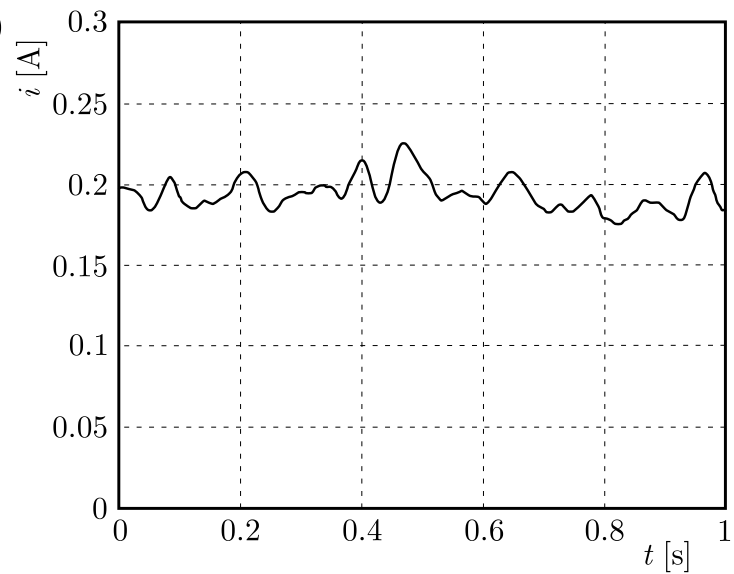

Fig. 14. Time history of voltage (a) and current (b) in the damper coil in case 2, $\omega=80 \mathrm{rpm}$

\section{Generator-MR damper system}

The tested system is indicated by a broken line in the experimental set-up shown in Fig. 15 . The diagram of the measurement and control system (see Fig. 16) comprises an AD/DA board by CompacDAQ (http://sine.ni.com) connected to a PC, a drive controller (MINT Drive II) supported by Mint Workbench software (http://www.baldormotion.com) controlling the electric motor in the drive system and by LabView software operating under MS Windows. The measured quantities included the speed $\omega$, emf in the generator $e$, voltage $u$, current $i$ and torque $T$ in the damper. The sampling frequency was $1 \mathrm{kHz}$.

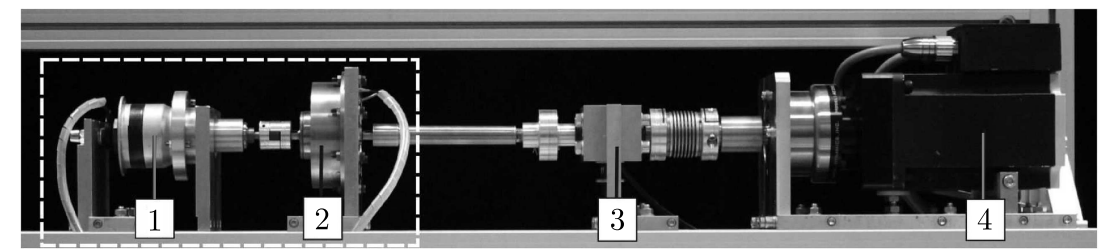

Fig. 15. Experimental set-up: 1 - generator, 2 - MR damper, 3 - torque meter, 4 - drive system

The first tests were conducted under idle run. The results are summarised in Fig. 17, showing time histories of the emf $e$ in the generator at the speed 10,30, $40 \mathrm{rpm}$. It seems that the emf varies over time and tends to grow with an increased speed. The variability range of emf is $0-4 \mathrm{~V}$ at $10 \mathrm{rpm}$ and $4-6 \mathrm{~V}$ at $30 \mathrm{rpm}$ and $6-7 \mathrm{~V}$ at $40 \mathrm{rpm}$. 


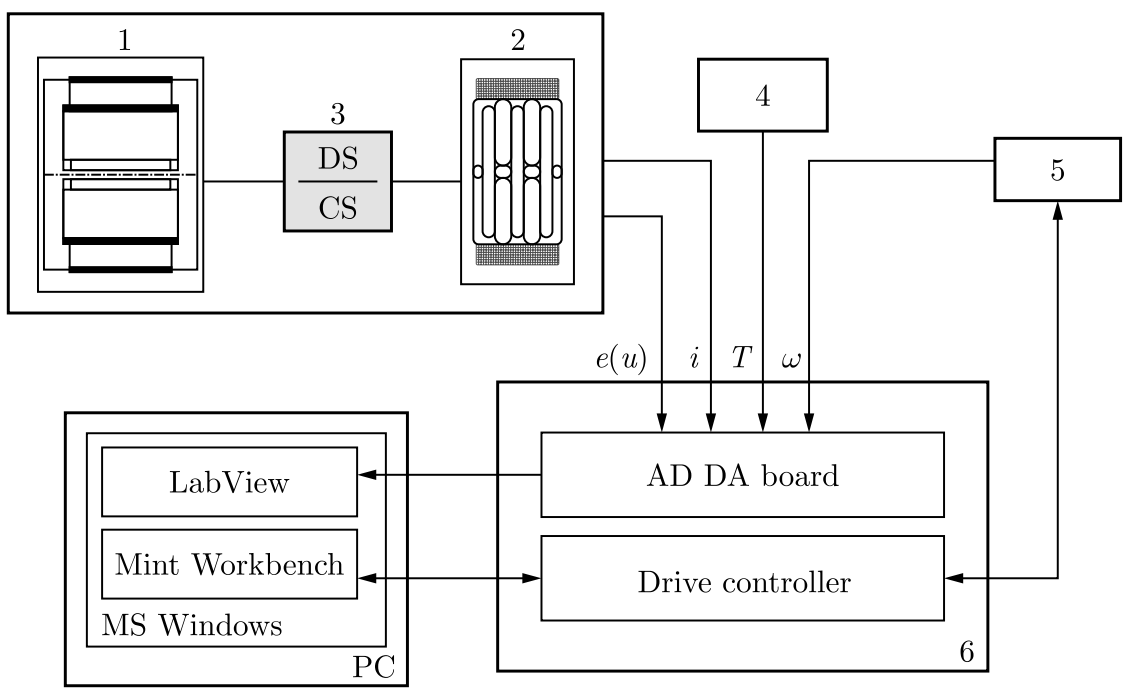

Fig. 16. Schematic diagram of the measurement and control systems: 1 - generator, 2 - MR damper, 3 - conditioning electronics, 4 - torque meter, 5 - drive system, 6 - switchbox

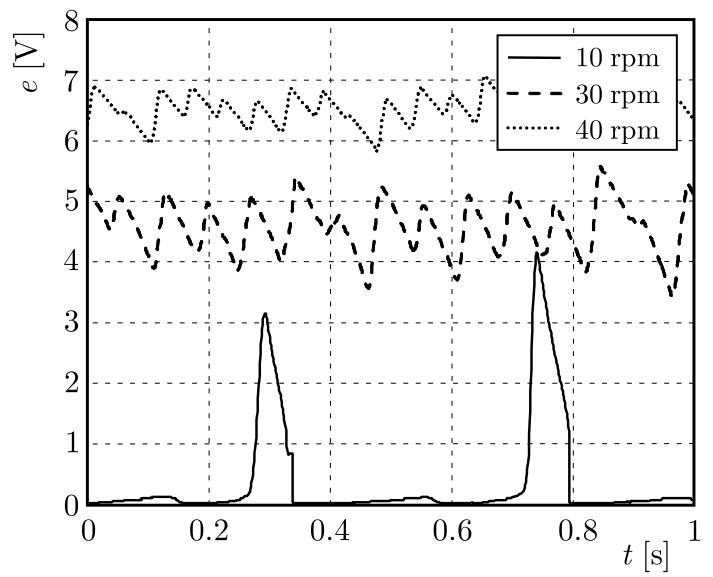

Fig. 17. Time patterns of emf in the generator at $\omega: 10,30,40 \mathrm{rpm}$

In the second stage of the experimental program, the testing was done on the system under load in the speed range $(10,90) \mathrm{rpm}$. Two distinct cases were considered:

- the coil in the generator was directly connected with the damper coil (case DS),

- the coil in the generator was connected to the damper coil via the electronics unit (case $\mathrm{CE})$.

Test results are shown in Fig. 18 (case DS) and Fig. 19 (case CE), plotting time histories of the voltage, current and torque in the damper at the speed $60,80,90 \mathrm{rpm}$. The results obtained for the two cases lead us to the following conclusions:

- in DS case, the voltage in the system increases with the speed whilst the maximal variability range is about $19 \mathrm{~V}$ at speed $60 \mathrm{rpm}$ and $22 \mathrm{~V}$ at speed $90 \mathrm{rpm}$,

- in CE case, the voltage in the system also increases with speed, and its variability range is $4-8 \mathrm{~V}$ at speed $60 \mathrm{rpm}$ and $3-7 \mathrm{~V}$ at speed $90 \mathrm{rpm}$,

- the largest levels of current are registered in case CE at the speed $80 \mathrm{rpm}$,

- in DS case, the torque delivered by the device does not change with the speed,

- in $\mathrm{CE}$ case, the torque increases with the speed. 
(a)

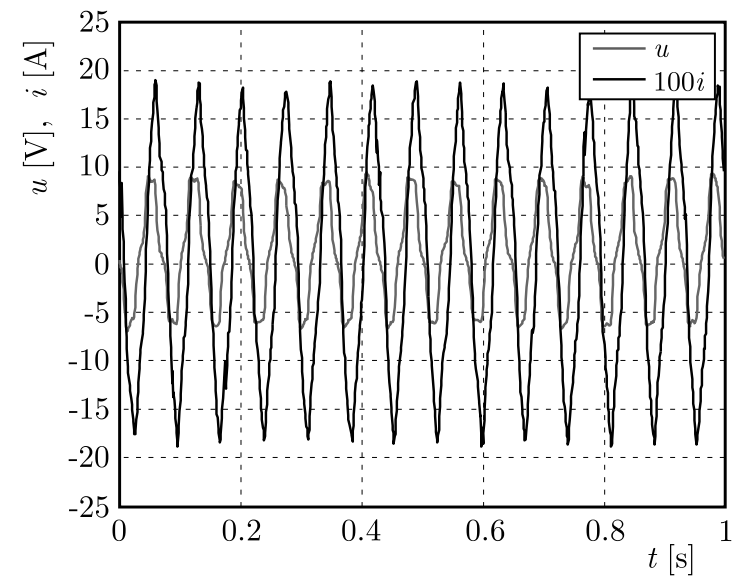

(b)

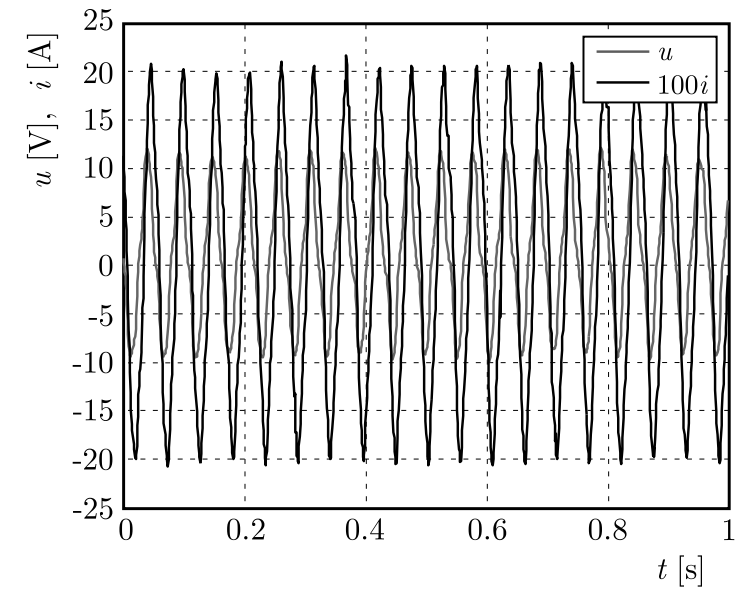

(c)

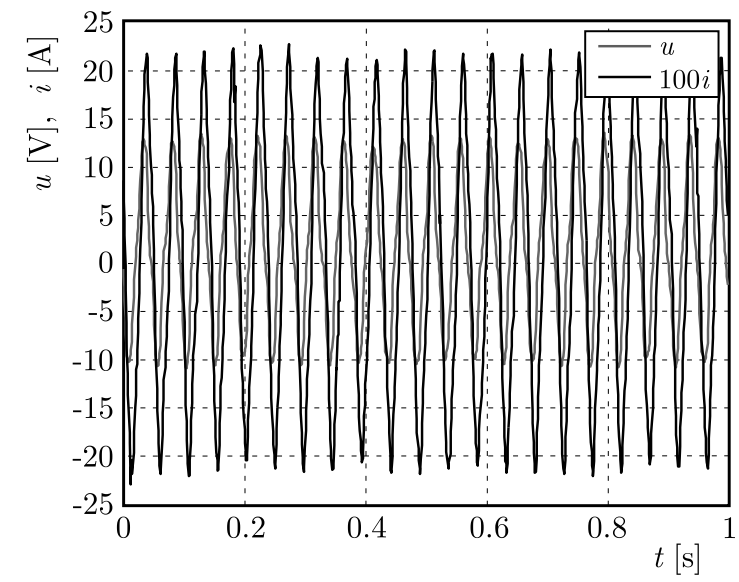

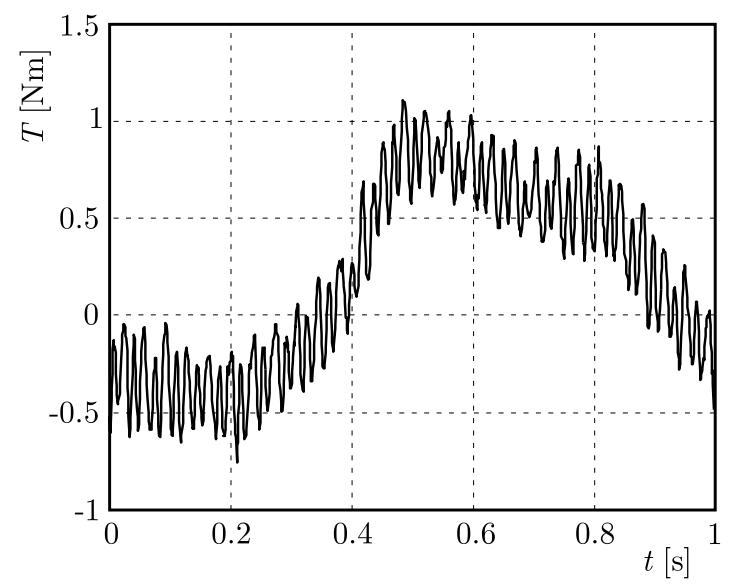
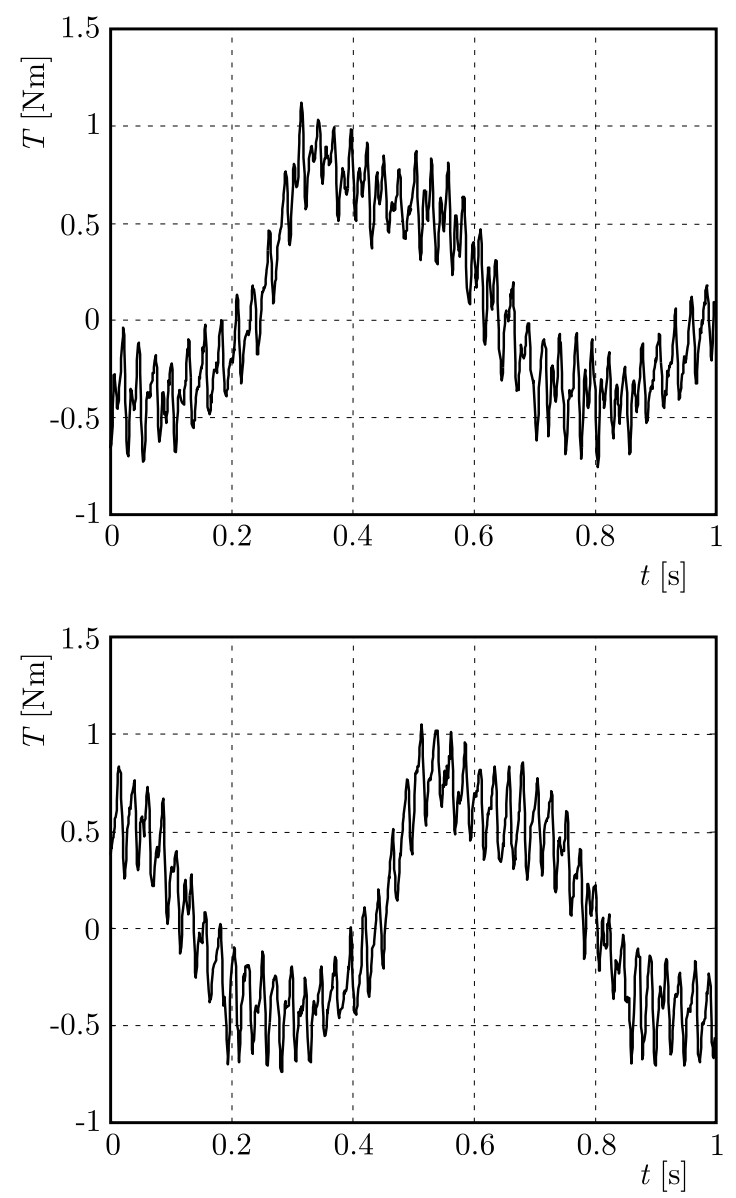

Fig. 18. Time histories of voltage, current and torque in the system in case DS: (a) $\omega=60 \mathrm{rpm}$,

(b) $\omega=80 \mathrm{rpm},(\mathrm{c}) \omega=90 \mathrm{rpm}$

\section{Summary}

The study summarises research investigations of an energy harvesting system utilising rotary motion. The system is composed of: a rotary MR damper, a rotary power generator and a conditioning electronics unit. The material summarises experimental testing of each system component and the whole system.

The research investigations lead us to the following conclusions:

- a change in the speed during idle run leads to a change in the amplitude and pattern of the emf in the generator, 
(a)

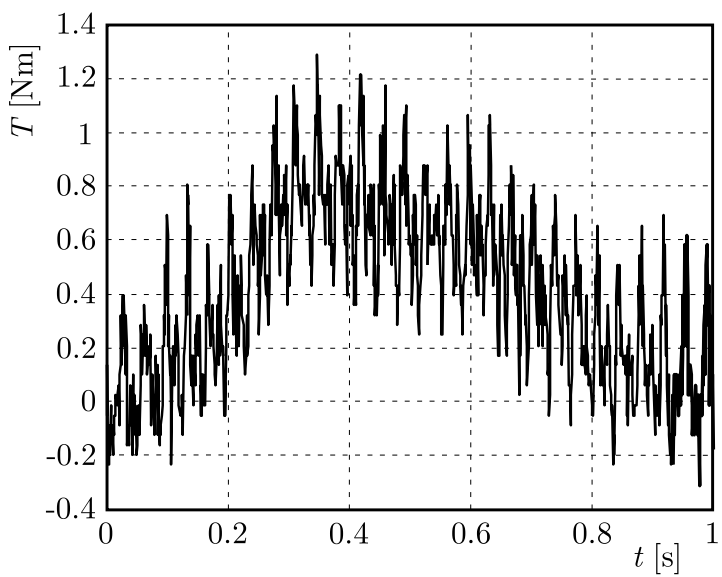

(b)

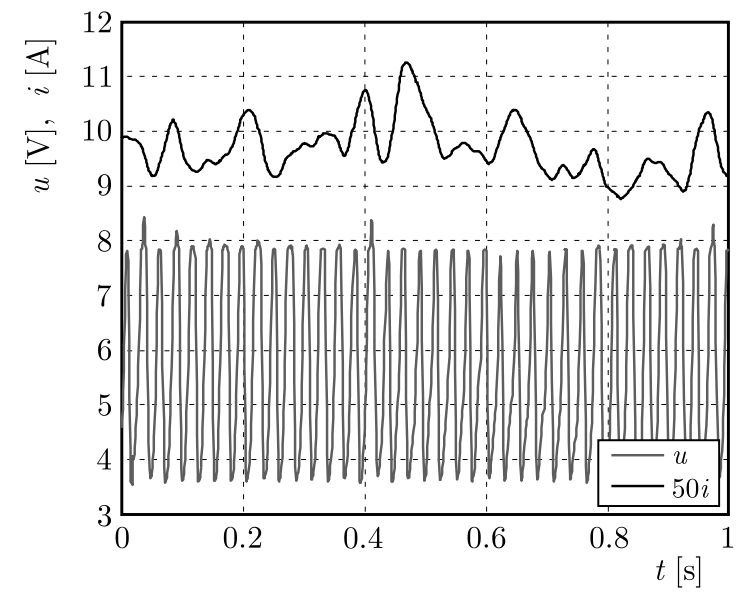

(c)

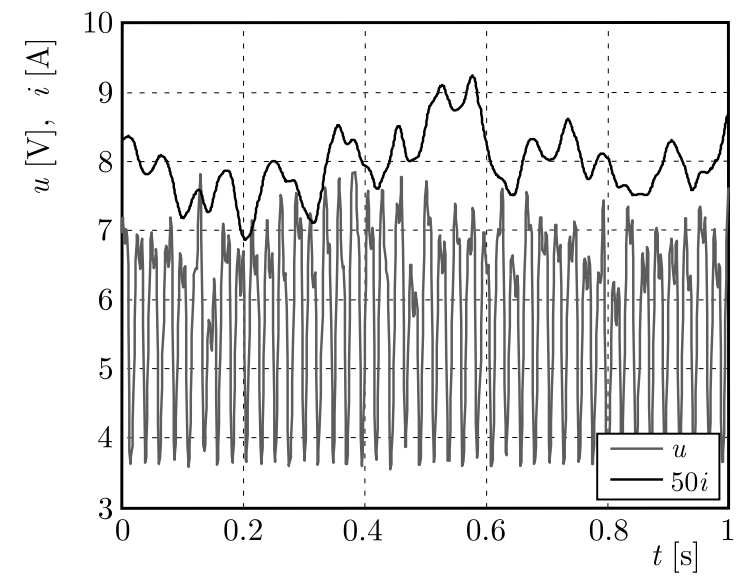

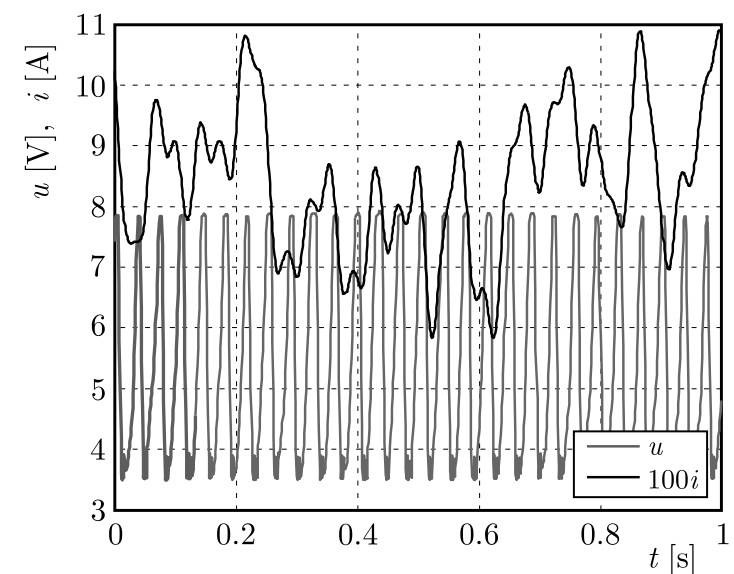
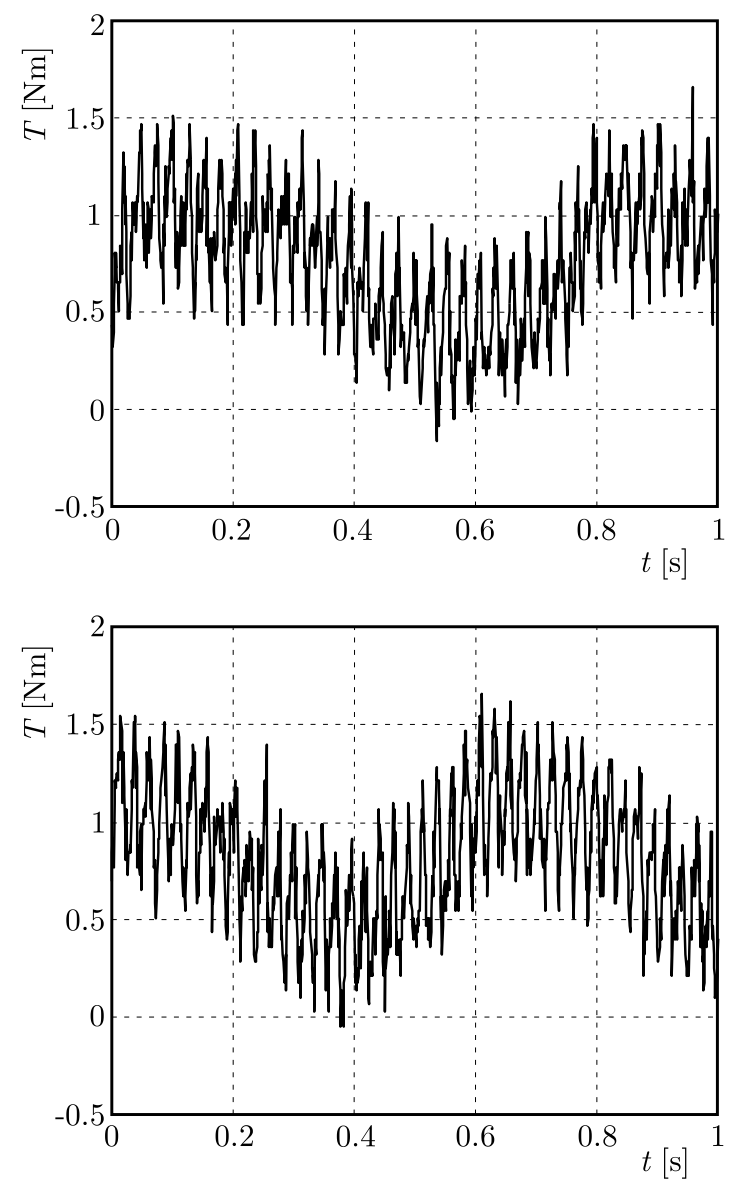

Fig. 19. Time histories of voltage, current and torque in the system in case CE: a) $\omega=60 \mathrm{rpm}$, (b) $\omega=80 \mathrm{rpm},($ c) $\omega=90 \mathrm{rpm}$

- parameters of the electrical circuit models are nonlinear functions of speed,

- energy recovered by the generator is sufficient to power the device, though it may prove insufficient at velocities below $10 \mathrm{rpm}$ when the generator output voltage is rather small and further reduced due to voltage drops across the diodes in the Graetz bridge,

- the voltage range handled by the converter has to be extended since the conditioning electronics unit performs better when the generator output voltage should not exceed $8 \mathrm{~V}$.

The system investigated provides a smart solution with potential applications to control of rotary motion. The main advantage of the system is its easy adaptability to external excitations and the fact that no external power supply unit is required. 
Further research efforts will focus on developing a different design structure of the generator and a more universal conditioning electronics unit.

Acknowledgement

This research is supported by the National Centre for Research and Development under grant No. NR03-0046-10.

\section{References}

1. Avadhany S., Abel P., Tarasov V., Anderson Z., 2008, Regenerative shock absorber, US Patent 8376100

2. Chen C., Liao W.H., 2012, A self-sensing magnetorheological damper with power generation, Smart Materials and Structures, 21, 025014

3. Cho S.W., Jung H.J., LeE I.W., 2007, Feasibility study of smart passive control system equipped with electromagnetic induction device, Smart Materials and Structures, 16, 2323-2329

4. Choi Y.T., Werely N.M., 2009, Self-powered magnetorhelogical dampers, Journal of Vibration and Acoustics, 131, 44-50

5. Hong J.H., Choi K.M., Lee J.H., Оh J.W., Lee I.W., 2007, Experimental study on smart passive system based on MR damper, Proceedings of the 18th KKCNN Symposium on Civil Engineering, Taiwan

6. http://sine.ni.com; CompacDaQ Technical Information

7. http://www.baldormotion.com; Mint Workbench Technical Information

8. http://www.allegromicro.com; Allegro MicroSystems LLC, ACS712 Hall-Effect Current Sensor IC, Technical Information

9. http://www.basonetic.com; MR-Fluid Basonetic ${ }^{\circledR} 2040$ Technical Information

10. http://www.nxp.com/documents/data_sheet/PMEG3050EP.pdf

11. Jung H.J., Jang D.D., Koo J.H., Chо S.W., 2010, Experimental evaluation of a self-sensing capability of an electromagnetic induction system designed for MR dampers, Journal of Intelligent Material Systems and Structures, 21, 837-836

12. Li Z., Zhuo L., Kunng J., Luhrs G., 2013, Energy-harvesting shock absorber with a mechanical motion rectifier, Smart Materials and Structures, 22, 028008

13. Liao W.H., Chen C., 2012, Self-powered, self-sensing magnetorheological dampers, US Patent Application No: 2012/0031,719

14. Microchip Technology Inc., PIC18F47J53 Family Data Sheet, 2010

15. Opera-3d version 15R2, User Guide, Cobham Technical Services, Vector Fields Software, 2011

16. Priya S., Inman D., 2009, Energy Harvesting Technologies, Springer Science+Business Media

17. SAPIŃSKi B., 2011, Experimental study of a self-powered and sensing MR damper-based vibration control system, Smart Materials and Structures, 20, 105007

18. SAPINSKI B., 2014, Energy harvesting MR linear damper: prototyping and testing, Smart Materials and Structures, 23, 035021

19. Scruggs J.T., Lindner D., 1999, Active energy control in civil structure, Proceedings of SPIE Conference on Smart Systems for Bridges, Structures and Highways

20. WANG D.H., WANG T., 2010, An integrated relative displacement self-sensing magnetorheological damper, Smart Materials and Structures, 19, 105008 